\title{
DEVELOPMENT OF A SEMI-AUTOMATED SYSTEM FOR ROUTINE PREPARATION OF CARBONATE SAMPLES
}

\author{
N Tisnérat-Laborde ${ }^{1,2} \bullet \mathrm{J} \mathrm{J}$ Poupeau $\bullet \mathrm{J}$ F Tannau $\bullet$ M Paterne \\ Laboratoire des Sciences du Climat et de l'Environnement, UMR CEA-CNRS 1572, Avenue de la Terrasse, \\ F-91198 Gif-sur-Yvette, France
}

\begin{abstract}
We constructed a semi-automated system to transform carbonate samples to $\mathrm{CO}_{2}$, as a means to increase sample-processing capacity. The physico-chemical process includes hydrolysis of carbonate, quantification of the mass of carbon and $\mathrm{CO}_{2}$ collection in a glass ampoule. The system is computer-controlled and monitored, and all the data are stored. A single run of five consecutive samples requires about 3.5 hours. Measurements of ${ }^{14} \mathrm{C}$ concentrations were made on samples of IAEA C-1 Carrara marble to test the reliability of this semi-automated system. These measurements have allowed the determination of the total system background and the memory effect of our system.
\end{abstract}

\section{INTRODUCTION}

The Radiocarbon group at the Laboratoire des Sciences du Climat et de l'Environnement (LSCE) handles numerous carbonate samples for paleoclimatic, oceanographic, and radiocarbon calibration studies. As a means to reduce the time and effort of sample processing, we developed a semi-automated instrument to transform carbonate samples into $\mathrm{CO}_{2}$ (Figure 1). In this paper, we describe this instrument and the principles of its use. We also present results of measurements to test the reliability of the system.

\section{METHODS}

\section{Carbonate Pretreatments}

Most of the carbonate samples analyzed in our laboratory include mollusk shells, corals and foraminifera shells. Mollusk shells and corals are first cleaned mechanically with sand blaster to remove superficial carbonate contaminant. This pretreatment reduces the weight of the sample by about 20$30 \%$. Then, samples are crushed in an agate mortar into a fine powder. That powder is then weighed and introduced into a glass reactor. Subsequently, the samples are rinsed with Milli-Q water. Foraminifera are only weighed (approximately $5-15 \mathrm{mg}$ ) and introduced in the glass reactor.

After this pretreatment, all samples are leached with $\mathrm{HNO}_{3}$ at $10^{-2} \mathrm{M}$ for 15 min, ultrasonically cleaned for $1 \mathrm{~min}$, and rinsed with Milli-Q water to remove superficial contamination.

Subsequently, we add $1 \mathrm{~cm}^{3}$ of pure $\mathrm{H}_{3} \mathrm{PO}_{4}(100 \%)$, heated previously for 3 days at $105^{\circ} \mathrm{C}$ and stored under argon to remove water, into the glass reactor (Figure 2a). Then, the reactor with the wet sample and $\mathrm{H}_{3} \mathrm{PO}_{4}$ is rapidly connected via a "Rotulex" union with a Viton o-ring to the semi-automated vacuum line to reduce the adsorption of atmospheric $\mathrm{CO}_{2}$ (Schleicher et al. 1998).

\section{Graphite Target Preparation}

Preparation of the graphite target, slightly modified from Arnold et al. (1989) is obtained by direct $\mathrm{CO}_{2}$ catalytic reduction (Vogel et al. 1984). The weight of the catalyst Fe powder $(150 \mu \mathrm{m})$ represents 5 times the mass of carbon for samples of $0.5-2 \mathrm{mg}$. Iron is then introduced into a quartz tube,

\footnotetext{
${ }^{1}$ Corresponding author. Email: tisnerat@ 1sce.cnrs-gif.fr.

${ }^{2}$ Contributing authors also include the other members of the LSCE Radiocarbon team.
} 
which is connected to the graphite reactor via a 6.5 -mm Cajon Ultra-Torr connector. The total volume of the reduction line is approximately $8 \mathrm{~cm}^{3}$.

To reduce memory effects, the quartz tube and the reduction lines are pumped and heated at $650{ }^{\circ} \mathrm{C}$ and $100{ }^{\circ} \mathrm{C}$, respectively, for $5 \mathrm{hr}$. The iron powder is then heated at $300{ }^{\circ} \mathrm{C}$ with $1 \mathrm{bar}$ of $\mathrm{H}_{2}$ for $1 \mathrm{hr}$ and then it is evacuated. The reduction reaction occurs at $600{ }^{\circ} \mathrm{C}$ with excess $\mathrm{H}_{2}\left(\mathrm{H}_{2} / \mathrm{CO}_{2}=3\right)$, and is completely achieved after 5-7 hr. The iron-carbon powder is pressed with a torque of $5 \mathrm{~N}$.m into a flat pellet of $1 \mathrm{~mm}$ diameter. Targets are stored in sealed glass tubes filled with pure argon.

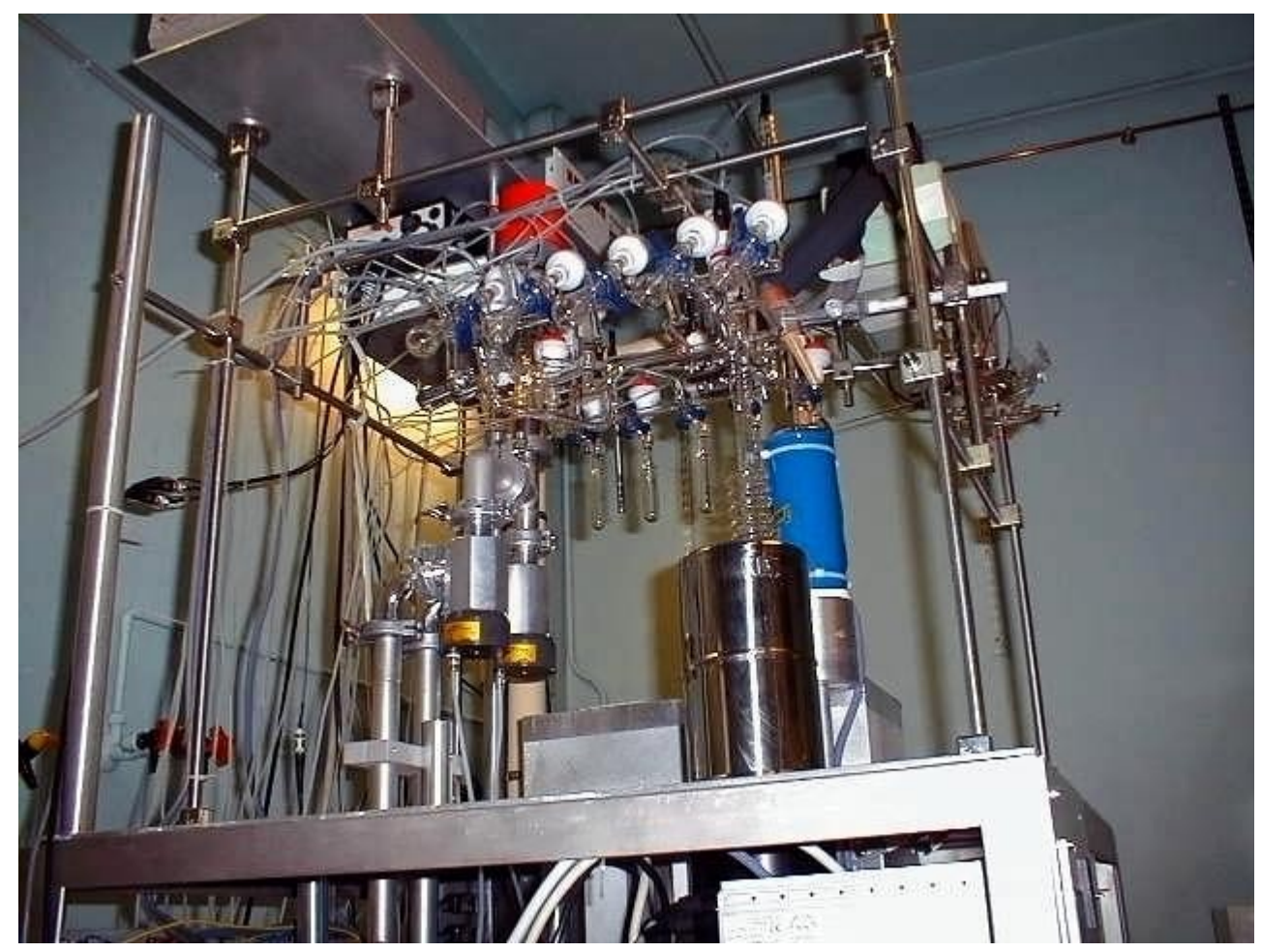

Figure 1 Photograph of the semi-automated carbonate system

\section{Description of the Semi-Automated System}

The system can run a series of five samples. The vacuum line, reactors, and ampoules are made of glass. The reactor is shaped to avoid the transfer of the fine particles into the vacuum line.

\section{The Components}

The semi-automated system includes the following components (Figure 2):

- A vacuum system composed of a primary pump and a turbomolecular pump.

- 3 electro-pneumatic valves to operate the vacuum system.

- 12 vacuum-actuated valves (vacutaps) to ensure the process. A vacuum reservoir connected to a membrane pump permits the opening/closing of all the valves.

- 2 Pirani gauges and 1 inverted magnetron gauge to measure the vacuum.

- A pressure transducer to read the pressure of the calibrated volume. 
- A water container, heated at $60{ }^{\circ} \mathrm{C}$ to hydrolyze the samples.

- 5 warm and cold traps, each one operating by a pneumatic-jack system:

"Water trap" A (Figure 2) containing a mixing of dry ice and ethanol at $-78{ }^{\circ} \mathrm{C}$.

" $\mathrm{CO}_{2}$ traps" $\mathrm{B}$ and $\mathrm{C}$, automatically filled with liquid $\mathrm{N}_{2}\left(-196{ }^{\circ} \mathrm{C}\right)$. Transfer of $\mathrm{N}_{2}$ is controlled by the electro-pneumatic valves of an adjacent liquid $\mathrm{N}_{2}$ storage reservoir and the adequate filling level secured through a thermocouple.

"Hot traps" D and E containing water at $40{ }^{\circ} \mathrm{C}$ and $60{ }^{\circ} \mathrm{C}$, respectively. D permits to expand the $\mathrm{CO}_{2}$ into the calibrated volume, E replaces the "water trap" A to remove water.

The entire system is monitored by a PC computer, controlled by software written in DELPHI (TurboPascal Object). The computer collects the external parameters, such as pressure, by an IEEE interface card through a digital multimeter. The electro-pneumatic valves, the vacuum actuated valves and the pneumatic-jack systems are connected via actuators to a 24-channel relay Output Board PC, then to the Data Acquisition Board (Digital I/0).

The software tests the vacuum on different parts of the line, monitors $\mathrm{CO}_{2}$ transfers, and measures corresponding pressures, until final storage in an ampoule. The process may be stopped, permitting manual procedures. All parameters, such as timing of the different steps, pressure limits may be modified before running the whole process.

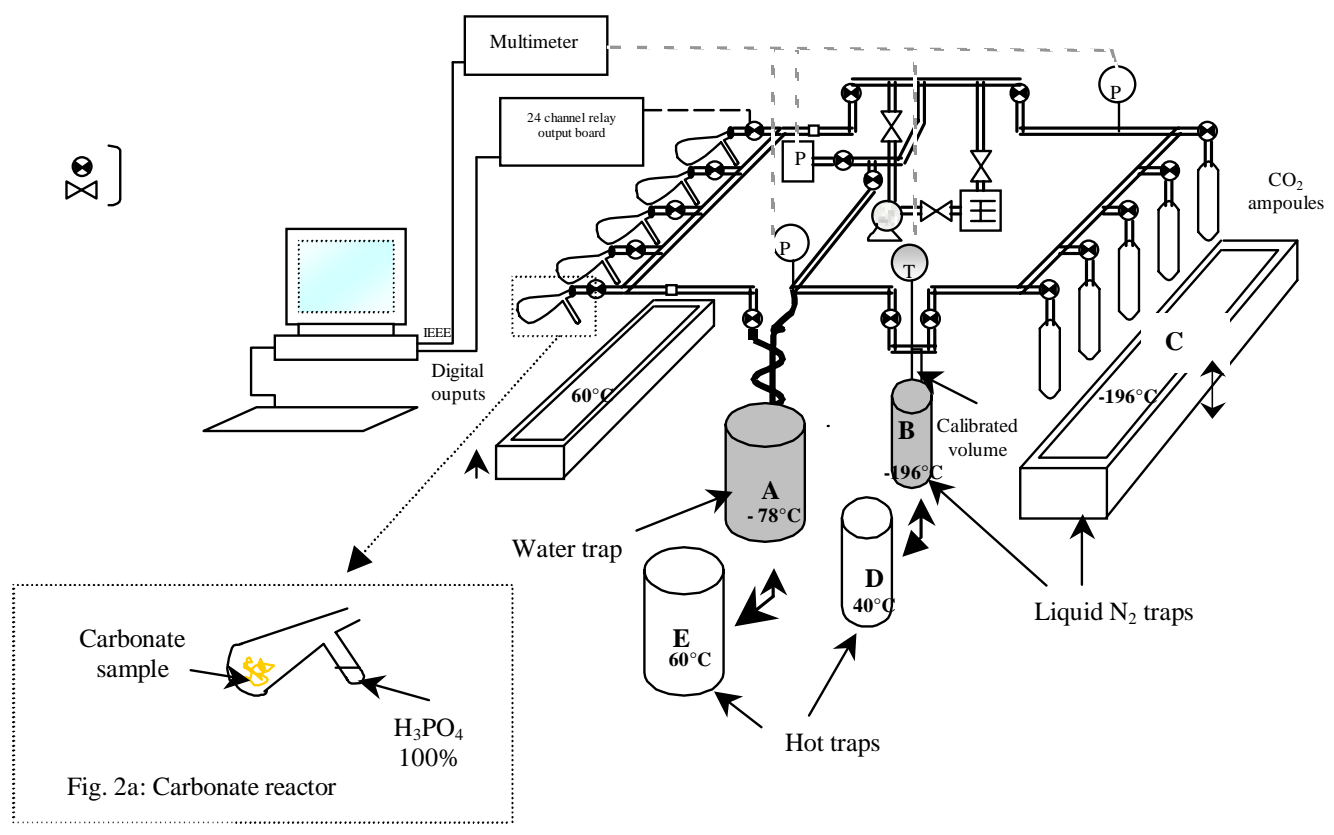

Figure 2 Schematic overview of the semi-automated carbonate system

\section{PROCEDURE}

Before connecting the five reactors to the semi-automated system, they are primarily connected to an adjacent vacuum line, and evacuated for $8 \mathrm{hr}$ until the pressure $<1.10^{-5} \mathrm{mbar}$ in a water bath at $60{ }^{\circ} \mathrm{C}$. The adjacent vacuum line has connections for two ramps of five reactors each. 
The evacuated ramp is connected via two "Rotulex" unions with a Viton o-ring to the semi-automated system. The entire process starts when the residual pressure is below $1.10^{-5} \mathrm{mb}$ after about an hour.

Each part of the vacuum line is first tested for leaks. Then, the five reactors are manually rotated. The five carbonate samples are dissolved in $\mathrm{H}_{3} \mathrm{PO}_{4}$. The hydrolysis of carbonate takes $15 \mathrm{~min}$. The "water trap" A and the two " $\mathrm{CO}_{2}$ traps" $\mathrm{B}$ and $\mathrm{C}$ are then automatically set up. The valve of the first sample is opened. The released $\mathrm{CO}_{2}$ goes through the "water trap" $\mathrm{A}$, and the gas is collected within trap B. Then, the "hot trap" D replaces the trap B. The dried $\mathrm{CO}_{2}$ expands into the calibrated volume where its pressure is measured and stored on the computer. Subsequently, the gas is cryogenically transferred into a glass ampoule with the "cold trap" C. Afterwards, traps A, D, and C are lowered.

The vacuum line is pumped for 10 min until a pressure $<1.10^{-5}$ mbar, while "hot trap" E removes residual water from the vacuum line. Then, the next sample may be transferred. One five-sample cycle requires about $3 \mathrm{hr} 30$ min with $\mathrm{H}_{3} \mathrm{PO}_{4}$ and carbonates evacuated apart.

\section{RESULTS}

\section{Background}

Contamination levels by modern carbon were tested on 49 samples of the ${ }^{14} \mathrm{C}$-free Carrara marble (IAEA C-1). This blank value includes contamination from the chemical pretreatment, from the semi-automated carbonate system and from the reduction vacuum lines.

Accelerator mass spectrometry (AMS) ${ }^{14} \mathrm{C}$ results obtained at the Gif-sur-Yvette Tandetron AMS facility are reported as a function of the mass of carbon in Figure 3. The ${ }^{14} \mathrm{C}$ values range from $0.02 \mathrm{pMC}$ to $0.25 \mathrm{pMC}$ for sizes of $1800 \mu \mathrm{g}$ to less than $200 \mu \mathrm{g}$. They show a large variability below $800 \mu \mathrm{g}$, and the highest ${ }^{14} \mathrm{C}$ value $(0.25 \mathrm{pMC})$ is obtained on the smallest sample $(<200 \mu \mathrm{g})$. Such a contamination level and its associated uncertainty (29\% at $1 \sigma$ ) are well above those of the other values. For this amount of carbon (around $200 \mu \mathrm{g}$ ), blank uncertainties of wood, charcoal, and Carrara marble generally are below $20 \%$ at $1 \sigma$ in our laboratory. Thus, this value is considered an outlier.

The plot of the ${ }^{14} \mathrm{C}$ data in pMC as a function of mass (Figure 3) would indicate a possible massdependence for contamination, as previously reported by several studies of ${ }^{14} \mathrm{C}$ background (Vogel et al. 1987; Kirner et al. 1995; Brown and Southon 1997; Schleicher et al. 1998). Using the method of least squares, the best fit between ${ }^{14} \mathrm{C}$ concentration versus the inverse of the mass of carbon (Figure 4) is obtained by:

$$
y=29.595 / x+0.0385
$$

where $y={ }^{14} \mathrm{C}$ concentration (pMC) and $x=$ mass of carbon $\left(\mu \mathrm{g}\right.$ ). The increase of ${ }^{14} \mathrm{C}$ background is due to the addition of a constant contamination equivalent of $0.6 \pm 0.3 \mu \mathrm{g}(1 \sigma)$ of modern carbon during the whole process.

For samples larger than $800 \mu \mathrm{g}$ of carbon, we can consider that the influence of this addition of contamination $(<1 \%)$ is negligible (see Figure 3). Moreover, the variability of the ${ }^{14} \mathrm{C}$ values $(n=28)$ is not significant. The ${ }^{14} \mathrm{C}$ values are statistically indistinguishable $\left(\chi^{2} ; \mathrm{P}_{0.05}=38.75 / 40.10\right)$ and the standard deviation is equal to the uncertainty at about $\pm 0.02 \mathrm{pMC}$. Therefore we consider that the background concentration for large samples is $0.06 \pm 0.02 \mathrm{pMC}$, which is equivalent to a ${ }^{14} \mathrm{C}$ age of about $60,000 \mathrm{BP}$. 


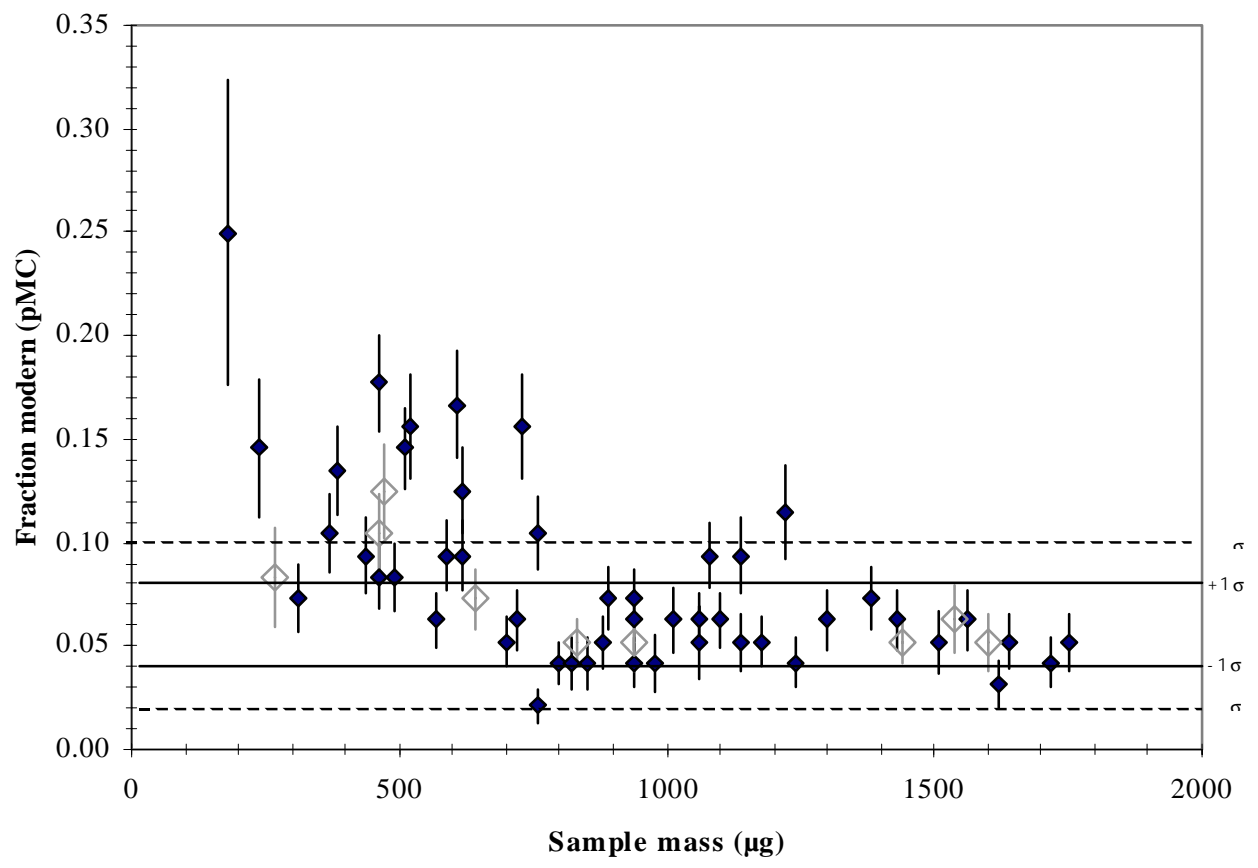

Figure $3{ }^{14} \mathrm{C}$ concentration (pMC) as a function of carbon sample mass $(\mu \mathrm{g})$. The error bars are shown as $\pm 1 \sigma$ (68\% of overall confidence). Data are distinguished by symbols. Solid diamonds: Carrara marble; open diamonds: Carrara marble for memory effect tests.

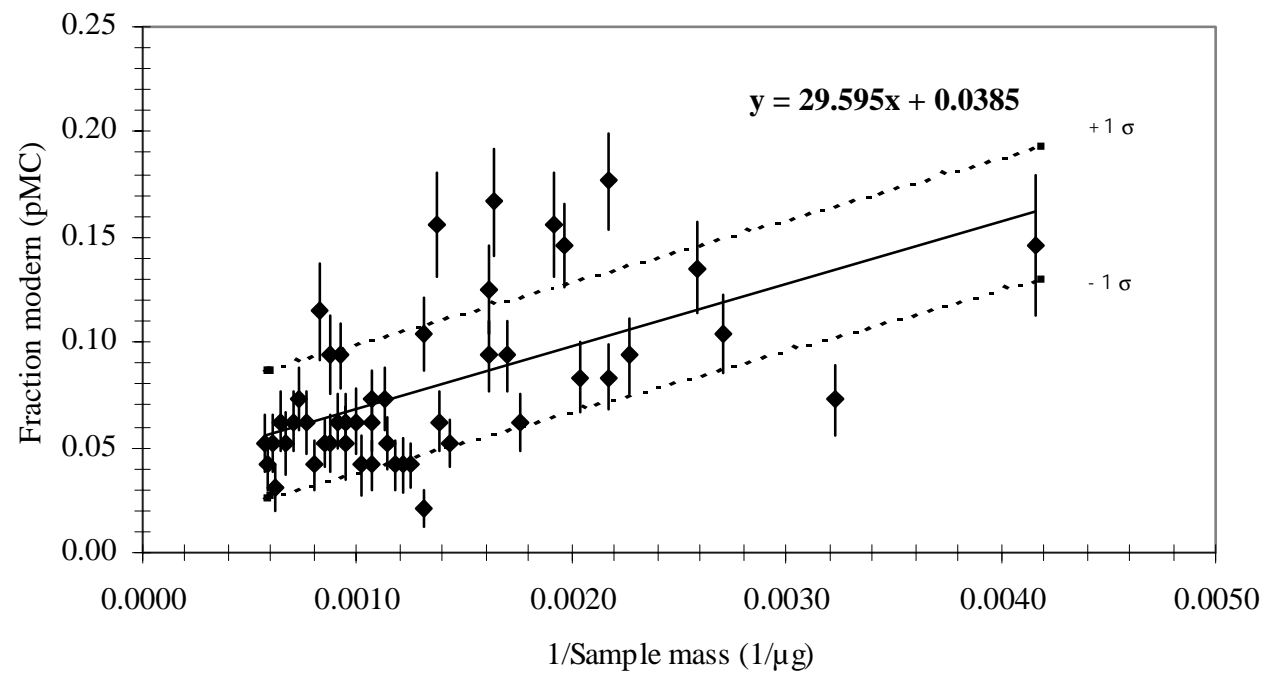

Figure 4 Relation of inverse carbon sample weight (IAEA C-1) on ${ }^{14} \mathrm{C}$ concentration (pMC). The error bars are shown as $\pm 1 \sigma(68 \%$ of overall confidence). 
Below $800 \mu \mathrm{g}$ of carbon, the ${ }^{14} \mathrm{C}$ values $(\mathrm{n}=20)$ show a larger spread with a standard deviation of $0.04 \mathrm{pMC}$, larger than the uncertainty at $0.02 \mathrm{pMC}$. The background values are tied to the mass of carbon.

Further tests will be developed in order to identify the source of contamination for 200-800 $\mu \mathrm{g} \mathrm{sam}$ ples particularly within chemical pretreatment, carbonate, and reduction processes and AMS ${ }^{14} \mathrm{C}$ measurements.

\section{Memory Effect}

Memory effect has been tested by alternate hydrolysis of carbonate samples at $94 \mathrm{pMC}$ and the $\mathrm{C}-1$ marble. We made two tests:

1. The hydrolysis of carbonate samples and blanks was made during the same cycle. The blank is processed after carbonate sample.

2. A five-sample cycle of carbonate samples has been followed by a series of five $\mathrm{C}-1$ samples.

The ${ }^{14} \mathrm{C}$ values are very similar to the previous blank determinations (Figure 3), showing that no memory effect proceeds into the whole system.

\section{CONCLUSION}

We built a semi-automated vacuum system for $\mathrm{CO}_{2}$ synthesis from carbonates to increase the number of sample processing capacity at the LSCE. We can routinely use this system to treat five samples within $3.5 \mathrm{hr}$, thereby allowing several runs of five-sample cycle per day. This semi-automated $\mathrm{CO}_{2}$ synthesis was tested through the AMS ${ }^{14} \mathrm{C}$ measurements of 49 samples of the IAEA C-1 Carrara marble. The results show a total system background at $0.06 \mathrm{pMC}$ with uncertainties of $0.02 \mathrm{pMC}$ for IAEA C-1 $>800 \mu \mathrm{g}$, equivalent to an age limit of about $60,000 \mathrm{BP}$. Below $800 \mu \mathrm{g}$, we observed a mass dependence of the background which is under investigation. The data show also no memory effect of the system.

\section{ACKNOWLEDGMENTS}

We would like to acknowledge the other members of the team, M Fontugne, C Hatté, and E Kaltnecker, for their help during the conception and test runs of the apparatus. We wish to thank Dr Maurice Arnold for measurements through the Gif-sur-Yvette Tandetron AMS facility (UMS 2004). This work was supported by the French CNRS and the CEA. LSCE contribution $n^{\circ} 0535$.

\section{REFERENCES}

Arnold M, Bard E, Maurice P, Valladas H, Duplessy JC. 1989. ${ }^{14} \mathrm{C}$ dating with the Gif-sur-Yvette Tandetron accelerator: status report and study of isotopic fractionation in the sputter ion source. Radiocarbon 31(3): 284-91.

Brown TA, Southon JR. 1997. Corrections for contamination background in AMS ${ }^{14} \mathrm{C}$ measurements. $\mathrm{Nu}$ clear Instruments and Methods in Physics Research B123:208-13.

Kirner DL, Taylor RE, Southon JR. 1995. Reduction in backgrounds of microsamples for AMS ${ }^{14} \mathrm{C}$ dating.
Radiocarbon 37(2):697-704.

Schleicher M, Grootes PM, Nadeau M-J, Schoon A. 1998 The carbonate ${ }^{14} \mathrm{C}$ background and its components at the Leibniz AMS facility. Radiocarbon 40(1):85-93.

Vogel JS, Nelson DE, Southon JR. 1984. Performance of catalytically condensed carbon for use in accelerator mass spectrometry. Nuclear Instruments and Methods in Physics Research B5:289-93.

Vogel JS, Nelson DE, Southon JR. 1987. ${ }^{14} \mathrm{C}$ background levels in an accelerator mass spectrometry system. $R a$ diocarbon 29(3):323-33. 